\title{
Effects of High Prevalence Anisakis in Fish Caught in the White Coast Médano, Falcon State, Venezuela on the Consuming Population
}

\author{
Héctor Bracho Espinoza \\ Technology Research Center, National Experimental University "Francisco de Miranda", Falcon State, Venezuela \\ Email address: \\ brachohector3@gmail.com
}

\section{To cite this article:}

Héctor Bracho Espinoza. Effects of High Prevalence Anisakis in Fish Caught in the White Coast Médano, Falcon State, Venezuela on the Consuming Population. Science Journal of Public Health. Vol. 4, No. 4, 2016, pp. 279-283. doi: 10.11648/j.sjph.20160404.12

Received: April 27, 2016; Accepted: May 7, 2016; Published: June 6, 2016

\begin{abstract}
In order to evaluate the effect of the high prevalence of parasites Anisakidae family, in fish caught in the fishing area Médano white, Falcon State, Venezuela; consumed by families of fishermen and villagers expended sector Pantano Abajo, municipality Miranda, Falcon state. The participatory diagnosis was made in the fishing area, in the consumer population and the dispenser Health Center (Ambulatory Urban) using unstructured interviews, surveys and review of medical records during the first half of 2013. An average of 1098 patient month has symptoms: asthma allergic diseases, diarrhea and vomiting, with percentages remains in a range that goes from $29.81 \%$ to $38.43 \%$. $68 \%$ of fishermen dispense fish without sanitary permit. Fishermen and consumers are likely to be accidental hosts of the parasite, not having adequate prevention levels.
\end{abstract}

Keywords: Anisakidae, Mugil Liza, Mugil Curema, Eugerres sp, Asthma, Diarrhea

\section{Introduction}

Public health is the responsibility of governments who are responsible for the organization of all services and activities that directly and indirectly contribute to the health of the population. Hence there must be a high responsibility and dispensing community health sector, to identify public health problems, analysis and application of sanitary measures for the benefit of all. According to the United Nations Food and Agriculture Organization (FAO) [16], it argues that a fundamental aspect is feeding people, where fishery products intended for human consumption, require vigilance, either fresh, frozen or processed, to control derived infections or associated with consumption of raw fish dishes, insufficiently cooked or lightly salted, smoked or marinated; which it is associated with cultural factors in certain populations, such as: the Japanese and consumption of suchi and sashimi and ceviche and Peruvian; and has become popular in the United States, European countries and South America; consumers predisposing to infection with gastrointestinal symptoms (anisakiasis) or allergic nature caused by parasites which have zoonotic nature such as: (Anisakis simplex, Anisakis spp Contracaecum osculatum and Pseudoterranova decipiens); they are living in the digestive tract and mesentery of many species of fish, crustaceans and molluscs [8]. The importance of this problem is now time to market or traveling direct sale of fishery products from various sources, ignoring the consequences of consumption of these products parasitized. It is necessary to minimize risks in the population of disease resulting from the ingestion of infected marine products, through health education programs, where preventive action is contemplated application. The objective of this research was to evaluate the effect of the high prevalence of parasites family Anisakidae detected in the fishing area and its influence on the clinical history of fishermen and consumers who can be inferred that the health conditions that records are associated with contact with the parasite.

\section{Literature Review}

There are proven scientific evidence suggests that consumption of parasitized fish the Anisakidae family raw or undercooked, causes health problems to humans, associated with immediate hypersensitivity reactions to antigens of Anisakis simplex, mediated by IgE antibodies to antigens anisakis, ie, in response to allergens parasite, as well as, 
anisakiasis with symptoms of fullness, epigastric pain, diarrhea and vomiting; when man becomes accidental host of the parasite [1], [7], [19], [17], [2]. In Latin America, human infection with these parasites was described in Chile, Peru and Brazil, [11], [8].

Anisakiasis is a common disease worldwide, although in Venezuela, is considered non-existent or under-reported due to ignorance caused by ingestion of larvae Anisakidae family [3], [4], [10], [18]. As a precautionary measure the culinary rule that the fish should be eaten cooked (boiled or fried) or previously frozen at $-20^{\circ} \mathrm{C}$ for $48-72$ hours and may use lower temperatures is recommended [9], [15], [13].

The level of information about parasites Anisakidae family in the world recorded an increase, without neglecting the knowledge of their evolutionary cycle linked to the aquatic environment as well: mammals such as whales (Balaenoptera musculus) and dolphins (Delphinus delphis) with parasites in the digestive tract, excrete eggs that hatch in water, will become larval stage 2, which are microscopic, free swimming and are able to survive 2-3 months. Being swallowed by young members crustaceans bodies planktonic (first intermediate host), the hatch into larvae in stage 3 , which are infective for fish and squid, which once ingested, migrate from the intestine to the tissues, especially the peritoneal cavity and grow to macroscopic size from 3 inches or more in length in the gastric mucosa become adults. These larvae can be transmitted between fish predation [6], [2]. According to previous studies [3], [4], on the Coast of Médano white, specifically Golfete Coro, were caught fish from the Mugilidae family (Mugil liza), (Mugil incilis), (Mugil curema) and Gerreidae family (Eugerres plumieri) with high parasite loads (7-9 parasites per specimen) and high prevalence. it is an area where all the conditions exist to allow the presence of nematodes of the genus Anisakidae, due to the existence of large numbers of migratory birds act as hosts final, coupled with improper handling of captured uneviscerated immediately fish, allowing the parasite to migrate from the viscera to mesentery and muscles; without adequate freezing, potentiating the risk for fishermen and consumers of the municipality Miranda, Falcon state, Venezuela. These precedents substantiated the need to know the presence of the parasite, the degree of parasitism and its prevalence (see Table 1 ), in fish caught in waters off the coast of Médano Blanco, Golfete Coro, Miranda municipality, located in the north central region of the state Falcon, Venezuela and characterize an imminent risk.

Table 1. Generes of the Family anisakidae identified in samples of fish (Mugil liza or Mugil curema) and (Eugerres spp.) In the Golfete of Coro. Falcón state, Venezuela.

\begin{tabular}{l|l|l}
\hline Genera identified & $\begin{array}{l}\text { Percentage detected in Mugil liza o Mugil curema } \\
\text { and Eugerres spp } 2010^{*}\end{array}$ & $\begin{array}{l}\text { Percentage detected in Mugil liza o Mugil curema and } \\
\text { Eugerres spp. 2011* }\end{array}$ \\
\hline Contracaecum $\mathrm{spp}$ & $97 \%$ & $97 \%$ \\
Pseudoteranova $\mathrm{spp}$ & $3 \%$ & $3 \%$ \\
\hline
\end{tabular}

* Sampling Period

Source: [3].

Fish features prominently in the diet in many parts of the world place, gaining more importance in countries with long coastal extensions, [9]. The fish represented $15.7 \%$ of animal protein intake of the world's population and $6.1 \%$ of all protein consumed [16]. Fish from the Mugilidae family (Mugil liza or Mugil curema), not within the top ten marine fish species or estuarine capture, according to the Department of Fisheries and Aquaculture of the [16]. However, it represents for consumers of the coastal states of Venezuela potential for accidental infection anisakid nematodes [3], similar situation occurs in the Colombian coast risk because, according to reports from FAO in Colombia annual averages are captured 13.49 tons of Mugil liza for consumption, which means a potential risk to human health, because it can cause anisakiasis or hypersensitivity reactions due to the high prevalence $(80.9 \%$ to $100 \%$ ) and intensity parasitic (4-23) by anisakid reported by [14]; nevertheless, it has not been described anisakiasis any case, probably because the fish is usually consumed cooked and eviscerated. The high intensity and parasite prevalence reflected in the study of [14], in the Colombian Caribbean, showed the power of colonization of these two kinds of nematodes in the population of Mugil Incilis and Mugil curema and allowed categorizing in the first instance to smooth as high contributor to the life cycle of the Anisakidae family, especially because of its high prevalence and greater incidence, Contracaecun sp., Followed by Pseudoterranova $s p$. These results compared with those reported by [3], in the Golfete Coro, also in the Venezuelan Caribbean, show similar behavior over the life cycle of parasites aniskidae family; that should be taken into account.

\section{Materials and Methods}

In this research descriptive, not experimental direct observation of phenomena that may be associated with related parasites Anisakidae family disease was made, it is a cross-sectional study provided data on prevalence at a given point of time, and indicated transactional relationships between diseases and their causal factors in the population.

\subsection{Population and Sample}

In the area of influence of the study they were surveyed 80 families direct beneficiaries of artisanal fisheries and industry consumers Pantano Abajo, municipality Miranda, Falcon state, Venezuela. Following the guidelines of [5], a representative random sample of 26 families was taken.

\subsection{Instruments and Data Collection Techniques}

Due to the nature of the study defined as exploratory 
structured and unstructured interviews, direct observation and surveys were used, with open and closed questions in a participatory diagnosis.

\subsection{Study Area}

The coast of Médano Blanco is located in the Isthmus of white sand dunes, separates the waters of Cape La Vela de Coro, in the waters off its west coast at the eastern bank of Golfete of Coro, Miranda municipality Falcon state, geographically extends, in North-West South direction, between degrees: $11^{\circ} 31^{\prime}$ to $11^{\circ} 42^{\prime}$ North Latitude and $69^{\circ} 45^{\prime}$ west longitude. The climate in the area belongs to arid peninsular maritime classification and ranks Golfete Coro. The temperature with little variation averaging $26^{\circ} \mathrm{C}$. Rainfall is scarce, occurring between September and November.

\section{Results and Discussion}

This explanatory exploratory study, conducted through participatory diagnosis, interviews, surveys and direct observations made in the study area show that the Coast Médano Blanco, municipality Miranda, Falcon State, Venezuela persist predisposing factors (own evolutionary cycle of the parasite), as alleged by: [6], [8], [12], they do maintain and increase the prevalence of parasites in fish caught Anisakidae family and therefore an imminent risk to the health of fishermen and consumers in general remains; where [16], to ensure safe food to the population are not followed. Fishermen using as a method of artisanal fishing bottom trawling and seine (driftnet), spend the night fishing, do not remove the viscera, or refrigerated fish, marketed and consumed a product with increased risk of contamination, since the parasite may migrate into the fish intestines and peritoneum muscles. $68 \%$ of the fishermen sell the fish without any health permits, failing to fulfill the requirement for monitoring of marine products consumed by the population as established by the [16].

In the monthly activity log dispenser health center (Urban outpatient), Sector Pantano Abajo area of influence of this study, as the site room of fishermen and where they sell fish caught by monitoring during the months from January to June 2013, the prevalence of respiratory disorders (asthma) was evidenced by an average of 719.6 patients per month, which may be associated with immediate reactions hipersenbilidad Anisakis antigens mediated by $\mathrm{IgE}$ antibodies as a parasite response to allergens, as established studies by: [1], [7], [19], [17], [2] y [13]. Moreover also gastric symptoms (diarrhea and vomiting) in patients 378.5 / month, coinciding with those reported by [11], [8]; presented in Table 2.

Table 2. Casuistry related to respiratory and gastric symptoms in patients attending the center health dispenser (urban outpatient) of the sector Pantano Abajo, municipality Miranda, Falcon State, Venezuela, during the first half of 2013.

\begin{tabular}{llllllllll}
\hline Symptoms & January & February & March & April & May & June & Total & Average \\
\hline Asthma & 615 & 570 & 667 & 797 & 857 & 812 & 4318 & 719.6 \\
Di-Vo & 375 & 332 & 358 & 434 & 397 & 375 & 2271 & 378.5 \\
Total/Month & 990 & 902 & 1025 & 1234 & 1254 & 1187 & 6589 & 1098 \\
\hline
\end{tabular}

Legend: Di-Vo $=$ Diarrhea y Vomiting.

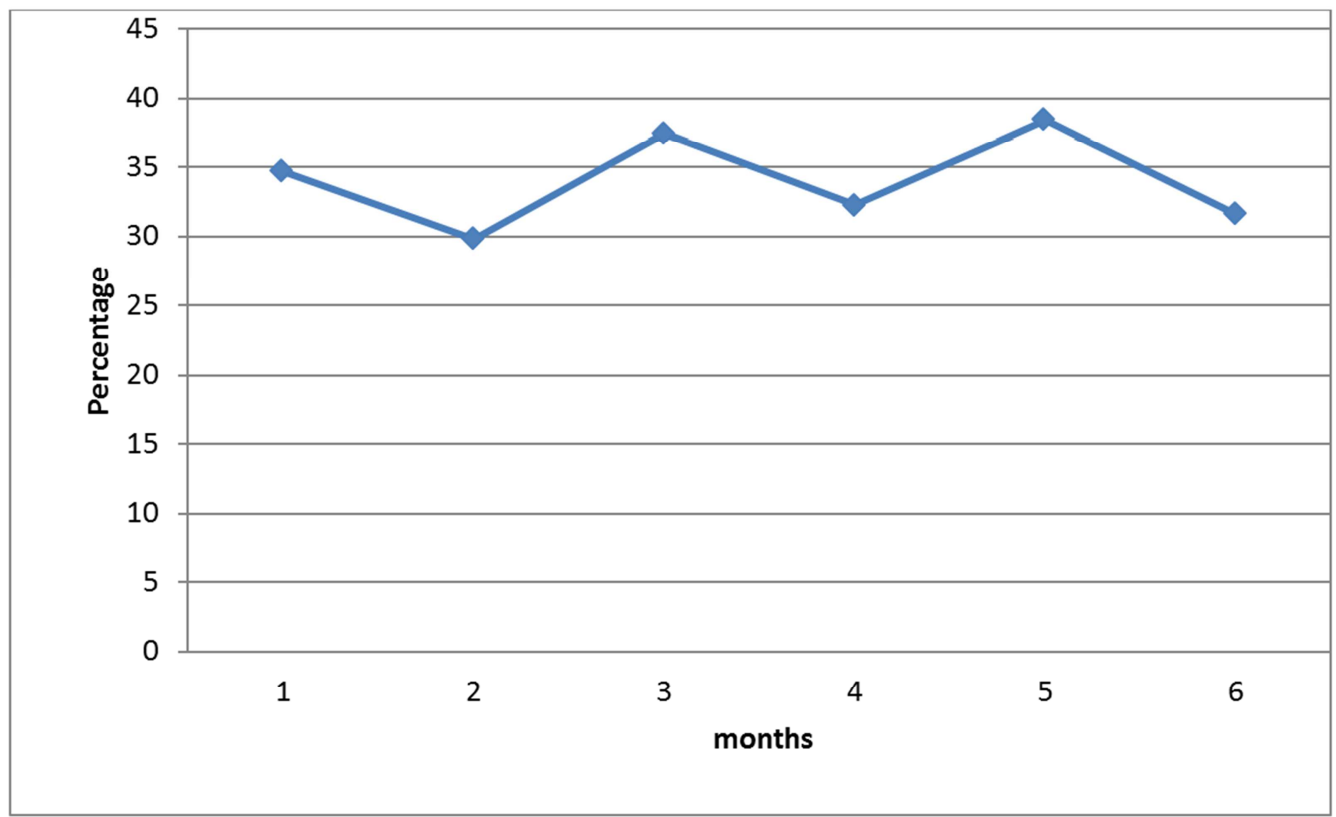

Figure 1. Percentage of patients with respiratory symptoms (asthma) and gastric (diarrhea and vomiting), who come to the health center dispenser of the sector Pantano Abajo, municipality Miranda Falcon State, Venezuela, during the months January to June 2013. 
In the run of the figure 1. You can see the behavior of the percentage of patients with respiratory and gastric symptoms attending the consultation, ranging from $29.81 \%$ to $38.43 \%$, showing that the matching symptoms with conditions generated by contact with family anisakidae parasites they are present; It is obvious due to the prevalence reported in the Coast Médano Blanco [3], [4]; and relating to symptoms reported intestinal anisakiasis [10]; [18]. That even if the diarrhea can be considered multifactorial, it would be necessary to know their links to more specific causal agents, as in this case are associated with the high prevalence of parasites anisakidae family.

According fishermen species of lower commercial value, the Mugilidae the family, with the highest prevalence of parasitosis Anisakidos, are consumed by their families, prepared by frying in a $65.38 \%, 3.8 \%$ consuming cooked and $26 \%$ make the salty; the latter form of preparation still presents risks of contamination to the consumer, if you take into account that by frying or cooked can inactivate the parasite by thermal effect. These mentioned features as problematic by:[9], [15], [13] y [3], regarding the processing and hygienic handling of marine products, are manifest in the study area and aggravate the situation, when observed very little knowledge by fishermen and consumers about this parasitism and its consequences. In addition to that $68 \%$ of fishermen marketed the product of fishing without sanitary permit, without any supervision or health inspection.

\section{Conclusions}

Symptoms prevailing according to the clinical history dispenser Health Center study area are: asthma linked to allergic processes; diarrhea and vomiting, which are cited as the main symptoms experienced individuals who have been in contact with family Anisakidae parasites, or their remains (chemicals secreted by the parasite); it is alarming that 1098 patients per month have symptoms asthma, diarrhea and vomiting, with a percentage that remains in a range that goes from $29.81 \%$ to $38.43 \%$.

The sources of pollution fish caught are understood to own the life cycle of the parasite, representing a serious risk to the health of fishermen, their families, as well as for the general population; and it is strengthened by the lack of sanitary inspection by the competent bodies, which are aggravated by dietary habit of eating raw fish salted, marinated in vinegar, or cooked in acid (ceviche), as are culinary mechanisms that do not guarantee complete elimination of the parasite or their remains, as well as its consequences.

The population of families linked to fishing activities in the Coast Médano Blanco, Miranda Municipality Falcon, known hygienic measures for processing fish once caught, do not have health permit for marketing thereof; is necessary the competent authorities to protect public health, scheduled days of inspection, health education and food handling, to mitigate the risk that runs through the exposed population and adapt to the current health legislation for marine products.

\section{References}

[1] Baeza M., J. M. Zubeldia and Rubio. 2001. Anisakis simplex Alergy. Journal of the World Allergy Organization. 13 (6): 242-249.

[2] Barros, C., F. Manzarbeitia and R. Lopez-Velez. 2008. Reactivity allergic to Anisakis simplex and its association with bronchial asthma in school children in the state of Nueva Esparta, Venezuela. Bulletin malariology and environmental health. Vol. XLVIII, No. 2.

[3] Bracho Espinoza H. 2014. Prevalence of parasitism by Anisakis in a sample of fish caught on the coastline of Golfete of Coro, Venezuela. Science Journal of Public Health. Vol. 2, No. 6, 2014, pp. 513-515. doi: 10.11648 / j.sjph.20140206.12

[4] Bracho-Espinoza, H.; Molina, J.; Pirona, M and M. Cordero 2013. Nematode of the Family Anisakidae in fishing products, Coastline Médano Blanco, Falcon State, Venezuela. Rev. Scientific, FCV-LUZ / Vol XXIII, No. 2, 163-167.

[5] Caicedo, C. 2006. Chapter III. Methodological Framework (. 16p) In: Educational Research. Experimental Pedagogical Libertador University. Coro Falcon State, Venezuela.

[6] Cuellar, M.; Fontanillas, J.; Pérez, J. 1991. Biology and epidemiology of larval anisakidosis. Disease herring. Complutense University. Madrid Spain. Rev. Cs. Vet. 4: 57-61.

[7] De la Torre, M., M. Rafaela, A. Pérez, B. Hernández, P. Jurado Gómez, E., E. Lasa E., and M. Anda. Allergy to Anisakis simplex 2003. Annals of the health system Navarra. España. 26: $25-30$

[8] Fernandez W. 2006. Parasitism in commercial fish and their impact on public health. Animal-Health Parasitology laboratory. CENIAP. http://www.ceniap.gob.ve (see September 2007).

[9] Gomez, J., M. Gérez; M. Zangroniz.; E. Wall; T. Gonzalez and M. Garcia. 2006. Hypersensitivity reactions and gastrointestinal manifestations caused by ingestion of Anisakis simplex parasitized fish. Semergen 25: 792-797.

[10] Hochberg, H. and Hamer, D. 2010. Hazards anisakidosis from the depths. Clin. Infect Dis. 51: 806- 812.

[11] Lantigua, I. 2006. Anisakis, the parasite of fish. gastric infections. Servicios Veterinarios del Departamento de Salud Pública. Cataluña, Spain. Online: http: //www.elmundo.essalud Medicine. Mundinteractivos, S. A. Accessed: 12.12. 2008

[12] Pardo, S., A. Sumac, H.; Noble and H. Suarez. 2008. Contracaecum sp (Anisakidae) Hoplias malabaricus in fish captured in the Cienaga Grande de Lorica, Cordoba. Journal MVZ Cordoba 13: 1304-1314 p.

[13] Rodriguez, M.; Tejada, M.; Gonzalez, M.; Moneo, I; Solas, M. 2011. The extraction methods and detection of antigens of Anisakis in food for human and animal consumption. Higher Council for Scientific Research (CSIC). The Biomedical Foundation Research Hospital Carlos III. Spain. It is Invention Patent 2,340,978 B1. Pp. 01-14.

[14] Ruiz, L. and Vallejo, A. 2013. Parameters of infection by nematodes of the family anisakidae that parasitize mullet (Mugil incilis) in the bay of Cartagena (Colombian Caribbean). Rev. INTROPICA. Vol. 8: 53-60. 
[15] Solas, M. T.; Moneo, I.; Tejada, M.; Muñoz, M.; Rodriguez, M.; Gonzalez, M. 2008. Anisakis antigens detected in the muscle of fish infected with Anisakis L3 simply degraded. J. Food Protec. 71: 1273-1276.

[16] United Nations Organization for Food and Agriculture (FAO). 2015. The State of World Fisheries and Aquaculture. Fisheries and Aquaculture Department of FAO, Rome, $242 \mathrm{pp}$.

[17] Takei, H, and S. Powel. 2007. Anisakidosis Intestinal (anisakiosis). Annals of Diagnostic Pathology 11: 350-352.
[18] Yasunga, H.; Horguichi, H.; Hashimoto, K.; Kuwabara, H.; Matsuda, S. 2010. The clinical features of intestinal anisakiasis in Japan. J. Am Trop. Med. Hyg. 83: 104-106.

[19] Zuloaga, J., J. Arias and J. Balibrea. 2004. Anisakiasis digestiva. Aspects of interest to the surgeon. Department of Surgery. Clinical Hospital San Carlos. Complutense University. Madrid. Spain. 75 (1): 9-25. 